\title{
Determination of Chlorpheniramine and Its Binding with Human Serum Albumin by Capillary Electrophoresis with Tris(2,2'- bipyridyl)ruthenium(II) Electrochemiluminescence Detection
}

\author{
Yingju LiU ${ }^{\dagger}$ and Wuyi ZHOU \\ Department of Applied Chemistry, College of Sciences, South China Agriculture University, \\ Guangzhou 510642, P. R. China
}

\begin{abstract}
Tris(2,2'-bipyridyl)ruthenium(II) electrochemiluminescence (ECL) detection in a capillary electrophoresis separation system was used for the determination of chlorpheniramine (CPM). The experimental conditions, such as the applied potential, separation voltage, injection voltage, injection time and the $\mathrm{pH}$ of the separation buffer were considered in detail. The ECL intensity showed two linear responses to CPM, i.e., from $15 \mu \mathrm{M}$ to $1 \mathrm{mM}$ and from $0.8 \mu \mathrm{M}$ to $15 \mu \mathrm{M}$ with a detection limit of $0.5 \mu \mathrm{M}$. The binding of CPM with human serum albumin was also monitored using this method and the binding constant was estimated to be $4.1 \times 10^{3} \mathrm{M}^{-1}$.
\end{abstract}

(Received December 7, 2005; Accepted April 4, 2006)

\section{Introduction}

Chlorpheniramine (CPM), 3-(4-chlorophenyl)-3-(2-pyridyl)propyl- $N, N$-dimethyl ammonium hydrogen, is one of the most potent antihistaminic agents in the treatment of allergic and vasomotor rhinitis, allergic conjunctivitis, mild urticaria, angioedema and as adjunct therapy in anaphylactic shock. ${ }^{1}$ Various methods are available for the determination of CPM, such as HPLC and LC, ${ }^{2}$ ion-selective electrode (ISE), ${ }^{3}$ and spectrophotometry. ${ }^{4}$ However, in HPLC and LC analysis, tedious sample clean-up procedures, such as extraction and purification, are always required; a drawback of the ISE method is that its response behavior is affected by the high background conductivity of the solution, the electrical properties of the film, and the electrical double-layer capacitance; some reactions are needed for spectrophotometry because of its significant overlapping in the spectra. Therefore, it is necessary to develop a more sensitive and effective method for CPM detection.

In the past two decades, capillary electrophoresis (CE) has become one of the most powerful and simple separation techniques for the analysis of complex mixtures because of its high resolution, short analysis time, and low operational cost. It has been widely used in the analysis of inorganic ions, organic substances, amino acids, DNA, protein, and so on. Various detection methods for $\mathrm{CE}$ are available, including $\mathrm{UV}$-visible absorbance, ${ }^{5}$ fluorescence, ${ }^{6}$ mass spectrometry, ${ }^{7}$ electrochemistry ${ }^{8}$ and electrochemiluminescence (ECL). ${ }^{9}$ Among them, ECL, as a special type of chemiluminescence (CL) in that the luminescence reagent is initiated by electrochemical reactions, has become an important and valuable detection technique in analytical chemistry in recent years. ${ }^{10,11}$ The major advantages of ECL are a reduction of interferences from solution impurities and elimination of the need for complicated construction of

$\dagger$ To whom correspondence should be addressed.

E-mail: liuyingju@ hotmail.com postcolumn reactors. ${ }^{12}$ Among all of the ECL reagents, $\mathrm{Ru}(\mathrm{bpy})_{3}{ }^{2+}$-ECL, as a simple and sensitive detection technique, has been applied to a wide variety of compounds and ions for alkylamines, ${ }^{13}$ amino acids, ${ }^{14}$ peptides, ${ }^{15}$ DNA,${ }^{16}$ due to its stability in aqueous media and high luminescence efficiency. Considering the tertiary amine structure of CPM, the short analysis time of $\mathrm{CE}$, and the high luminescence efficiency of $\mathrm{Ru}(\mathrm{bpy})_{3}{ }^{2+}-\mathrm{ECL}$, the detection of CPM by capillary electrophoresis with $\mathrm{Ru}(\mathrm{bpy})_{3}{ }^{2+}-\mathrm{ECL}$ is promising. As far as we know, fewer relative reports can be found.

Therefore, in this work, CE separation with end-column $\mathrm{Ru}(\mathrm{bpy})_{3}{ }^{2+} \mathrm{ECL}$ detection for the quantitative determination of CPM was performed. The experimental conditions, such as the injection voltage, separation voltage, injection time and the $\mathrm{pH}$ of the separation buffer were considered in detail. The association of human serum albumin (HSA) with CPM was also realized by combining equilibrium dialysis and $\mathrm{CE}-\mathrm{Ru}(\mathrm{bpy})_{3}{ }^{2+}$ ECL.

\section{Experimental}

\section{Reagents and solutions}

All of the reagents used were of analytical grade unless stated otherwise. Tris $\left(2,2^{\prime}\right.$-bipyridyl)ruthenium(II) chloride hexahydrate was obtained from J\&K Chemical Company, while HSA and the dialysis bag (14000 Da) were purchased from Sigma, and CPM from Xi' an Pharmaceutical Factory. A stock solution of $0.1 \mathrm{M}$ CPM was prepared in a phosphate buffer solution (PBS) ( $\mathrm{pH}$ 8.0), and stored at $4^{\circ} \mathrm{C}$. A series of standard solutions for the calibration curve and reproducibility were prepared by diluting the solution with PBS just before use. Double-distilled water was used throughout.

\section{Apparatus}

CE-ECL was from Xi'an Remax Tech. Ltd. Com. (China). The end-column ECL cell was composed of a three-electrode 


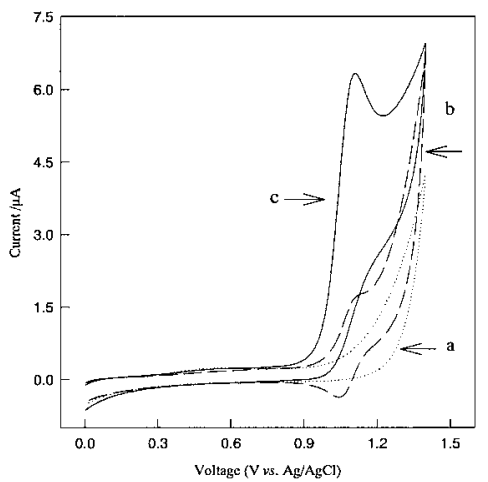

Fig. 1 Cyclic voltammograms for $\mathrm{Ru}(\mathrm{bpy})_{3}{ }^{2+}$ and $\mathrm{CPM}$ in a PBS buffer solution ( $\mathrm{pH}$ 8.0) at a bare Pt electrode. (a) Blank buffer solution only; (b) containing $5 \mathrm{mM} \mathrm{Ru}(\mathrm{bpy})_{3^{2+}}$; and (c) containing 5 $\mathrm{mM} \mathrm{Ru}(\mathrm{bpy})_{3}{ }^{2+}$ and $2 \mathrm{mM}$ CPM. Scan rate, $50 \mathrm{mV} / \mathrm{s}$.

system with a $300-\mu \mathrm{m}$ diameter Pt disc electrode as a working electrode, a Pt wire electrode as an auxiliary electrode, and $\mathrm{Ag} / \mathrm{AgCl}$ electrode as a reference electrode. A potentiostat was used to supply the potential of the oxidation of $\mathrm{Ru}(\mathrm{bpy})_{3^{2+}}$ to $\mathrm{Ru}(\mathrm{bpy}) 3^{3+}$ at the working electrode. A piece of capillary (i.d. $25 \mu \mathrm{m}$, o.d. $375 \mu \mathrm{m}$ ), from Yongnian Optical Conductive Fiber Plant (Hebei, China), cut to $50 \mathrm{~cm}$ in length, was used as a separation capillary and was placed between the injection reservoir and the reaction reservoir. A high voltage was applied at the injection end, with the reservoir in the ECL detection cell held at the ground potential. During the experiments, the highvoltage power-supply not only provided a separation voltage across the capillary to drive sample, but also introduced the sample by electromigration injection at a definite time. The detection cell was placed directly above the photo-multiplier tube. The biased potential was set at $800 \mathrm{~V}$. The sample was quantified using the ECL intensity. Before analysis, about 250 $\mu \mathrm{l}$ of the $\mathrm{Ru}(\mathrm{bpy})_{3}{ }^{2+}$ solution (PBS, $\mathrm{pH} 8.0$ ) was added into the reservoir, and refreshed every $2 \mathrm{~h}$ to eliminate the possible depletion effect or potential interference during the analysis. Before each run, the capillary was flushed with the corresponding running buffer until the baseline of CL was flat. All of these apparatus were controlled and data were collected with a programmable computer.

\section{Binding of HSA with CPM}

Equilibrium dialysis was applied to study the binding of HSA with CPM by incubating $150 \mu \mathrm{L}$ of $200 \mu \mathrm{M}$ HSA and $200 \mu \mathrm{L}$ $0.01 \mathrm{M} \mathrm{CPM}$ in the dialysis bag at $37^{\circ} \mathrm{C}$. The bag was then immersed in $4 \mathrm{~mL}$ of PBS, and $100 \mu \mathrm{L}$ of outside solution was detected every half hour until the ECL intensity was constant. Then, the binding constant was also estimated by fitting to the Langmuir equation. The UV-visible spectra of the solution outside or inside of the dialysis bag were detected before or after culture to confirm the binding of HSA with CPM.

\section{Results and Discussion}

\section{Cyclic voltammograms of $R u(\text { bpy })_{3}{ }^{2+}$ and $C P M$}

Cyclic voltammograms were performed on a CHI 660 A electrochemical workstation (Shanghai Chenhua Apparatus, China) with a conventional three-electrode system. Pt wire encapsulated in epoxy resin was used as the working electrode, with an $\mathrm{Ag} / \mathrm{AgCl}$ electrode as the reference electrode and a

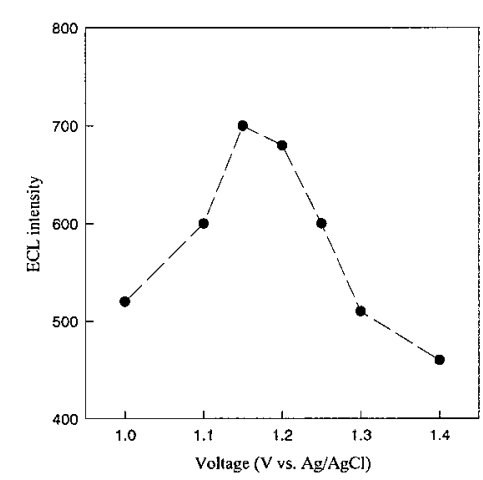

Fig. 2 Influence of the applied potential on the ECL intensity.

platinum electrode as the auxiliary electrode. Figure 1 shows cyclic voltammograms of $\mathrm{Ru}(\mathrm{bpy})_{3}{ }^{2+}$ in the presence or absence of CPM. Curve a shows no obvious peak in the cyclic voltammogram of a bare Pt electrode in a blank buffer solution (pH 8.0). In a buffer solution containing $5 \mathrm{mM} \mathrm{Ru}(\mathrm{bpy})_{3}{ }^{2+}$, the cyclic voltammogram displays reversible electrochemical properties with a peak-to-peak separation of about $59 \mathrm{mV}$ in continuous scanning (only one cycle shown here, curve b). In curve $\mathrm{c}$, in a solution containing $5 \mathrm{mM} \mathrm{Ru}(\mathrm{bpy})_{3}{ }^{2+}$ and $2 \mathrm{mM}$ CPM, the reduction peak becomes weaker, while an obvious electrochemical catalytic oxidation peak can be discovered. Continuous cycling caused a continuous decrease of the oxidation peak (not shown). ECL is a means for converting electrical energy into radiative energy. At the electrode, the reactive intermediates were produced from stable precursors, and then to form excited states that can emit light. According to earlier reports, ${ }^{9,17}$ the mechanism can be illustrated as follows:

$$
\begin{aligned}
& \mathrm{Ru}(\mathrm{bpy})_{3}{ }^{2+}-\mathrm{e} \longrightarrow \mathrm{Ru}(\mathrm{bpy})_{3}{ }^{3+} \\
& \mathrm{Ru}(\mathrm{bpy})_{3}{ }^{3+}+\mathrm{RR}^{\prime} \mathrm{NCH}_{2} \mathrm{R}^{\prime \prime} \longrightarrow \mathrm{Ru}(\mathrm{bpy})_{3}{ }^{2+}+\mathrm{RR}^{\prime} \mathrm{N}^{+} \cdot \mathrm{CH}_{2} \mathrm{R}^{\prime \prime} \\
& \mathrm{RR}^{\prime} \mathrm{NCH}_{2} \mathrm{R}^{\prime \prime}-\mathrm{e} \longrightarrow \mathrm{RR}^{\prime} \mathrm{N}^{+} \cdot \mathrm{CH}_{2} \mathrm{R}^{\prime \prime} \\
& \mathrm{RR}^{\prime} \mathrm{N}^{+} \cdot \mathrm{CH}_{2} \mathrm{R}^{\prime \prime} \longrightarrow \mathrm{RR}^{\prime} \mathrm{NC} \cdot \mathrm{HR}^{\prime \prime}+\mathrm{H}^{+} \\
& \mathrm{RR}^{\prime} \mathrm{NC} \cdot \mathrm{HR}^{\prime \prime}+\mathrm{Ru}(\mathrm{bpy})_{3}{ }^{3+} \longrightarrow \\
& \mathrm{Ru}(\mathrm{bpy})_{3}{ }^{2+*}+\text { oxidized product } \\
& \mathrm{Ru}(\mathrm{bpy})_{3}{ }^{2+*} \longrightarrow \mathrm{Ru}(\mathrm{bpy})_{3}{ }^{2+}+h v
\end{aligned}
$$

It was found that with the aid of $\mathrm{CPM}\left(\mathrm{RR}^{\prime} \mathrm{NCH}_{2} \mathrm{R}^{\prime \prime}\right)$, the quantity of $\mathrm{Ru}(\mathrm{bpy})_{3}{ }^{2+}$ could be greatly enhanced while $\mathrm{Ru}(\mathrm{bpy}) 3^{3+}$ decreased; therefore, the oxide current dramatically increased with a decrease in the reduce current.

\section{Optimization of experimental conditions}

Since the potential applied to the electrode had an effect on the rate of the light-emitting chemical reaction, it could influence the intensity of the emitted light. Therefore, the potentials of $1.0-1.4 \mathrm{~V}$ were investigated. In Fig. 2, it can be found that the ECL response increased if the potential increased from 1.0 to $1.2 \mathrm{~V}$, and then decreased after 1.2 V. From Fig. 1, it can be found that the maximum oxide current for $\mathrm{Ru}(\mathrm{bpy}) 3_{3}{ }^{2+}-\mathrm{CPM}$ system was at about $1.15 \mathrm{~V}$, so the highest response may have been at about $1.2 \mathrm{~V}$. However, when the potential was higher than $1.25 \mathrm{~V}$, the oxidation of water may have had a negative effect on the ECL intensity. Therefore, in our following 

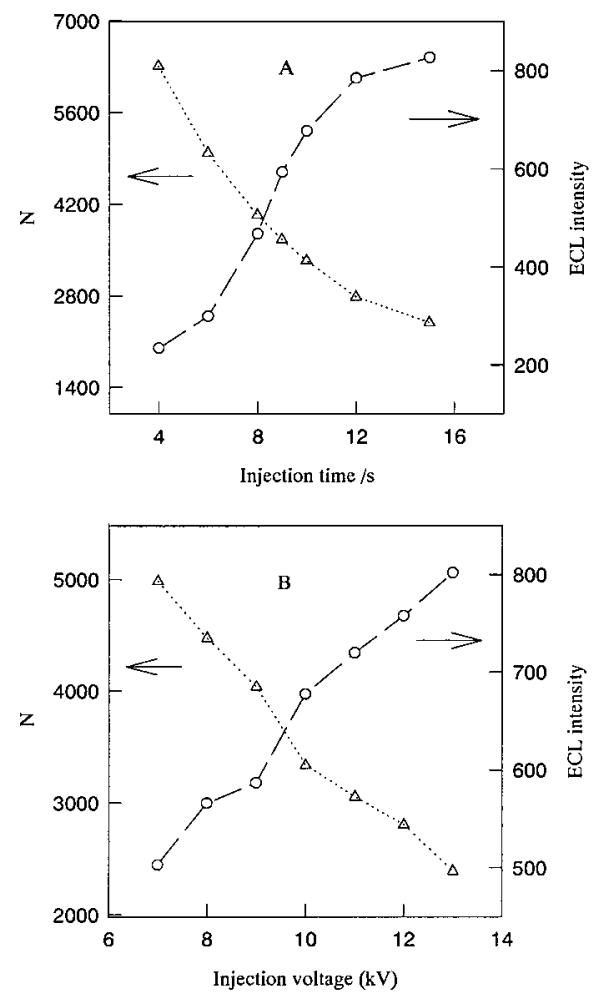

Fig. 3 Effect of the injection time (A) and the injection voltage (B) on the ECL intensity $(\mathrm{O})$ and the number of theoretical plates $(N ; \triangle)$ for $30 \mu \mathrm{M} \mathrm{CPM}$. The injection voltage was $10 \mathrm{kV}$ in $\mathrm{A}$ and the injection time was $15 \mathrm{~s}$ in $\mathrm{B}$. The separation voltage was $15 \mathrm{kV}$.

experiments, $1.2 \mathrm{~V}$ was set as the optimal detection potential.

The injection volume of the sample is another key experimental condition, since it can influence not only the sensitivity, but also the peak shape. Therefore, the effects of the injection voltage and the injection time on the ECL intensity were investigated in detail, which is shown in Fig. 3. With increasing the injection voltage over a range from 7 to $13 \mathrm{kV}$ and increasing the injection time from 4 to $15 \mathrm{~s}$, the ECL intensity increased, whereas the number of theoretical plates $(N)$ decreased. From Eqs. (1)-(6), the CPM concentration is relative to the electrochemiluminescence reaction rate, which has an influence on the emission intensity; therefore, at a higher injection voltage, more analyte appears on the surface of the working electrode, which produces a higher ECL signal. However, too much analyte could not immediately react at the electrode, and was dispersed into the solution, so the ECL peaks were usually broadened and $N$ decreased. Thus, to obtain a higher ECL signal and a larger $N, 10 \mathrm{kV}$ and $10 \mathrm{~s}$ was compromised as the optimal injection voltage and injection time, respectively.

The separation voltage was also investigated. With an increase in the separation voltage, the separation time decreased. However, no obvious variety in the ECL intensity was found. Considering a suitable separation time, $15 \mathrm{kV}$ was selected as the separation voltage.

The $\mathrm{pH}$ of the solution is an important factor that influences the $\mathrm{CL}$ reaction rate and the resolution, because the $\mathrm{Ru}(\mathrm{bpy})_{3^{2+}}$ ECL reaction with alkylamine is a $\mathrm{pH}$-dependent process, with the maximum emission being observed under a slightly basic condition. ${ }^{18}$ Therefore, the running buffer condition was tested from $\mathrm{pH} 4.5$ to 9 prepared from PBS. As shown in Fig. 4, with an increase in the $\mathrm{pH}$, the ECL response increases because of

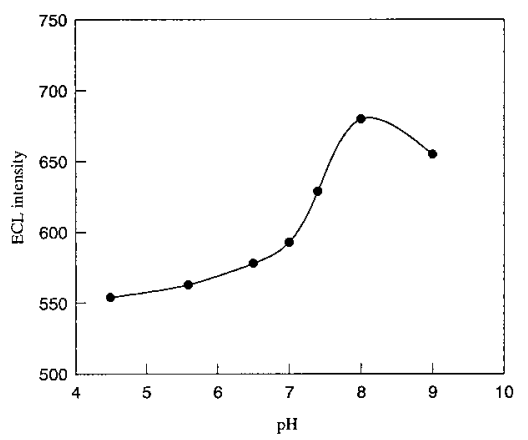

Fig. 4 Effect of the buffer $\mathrm{pH}$ on the ECL intensity of $\mathrm{Ru}(\mathrm{bpy})_{3}{ }^{2+}$.

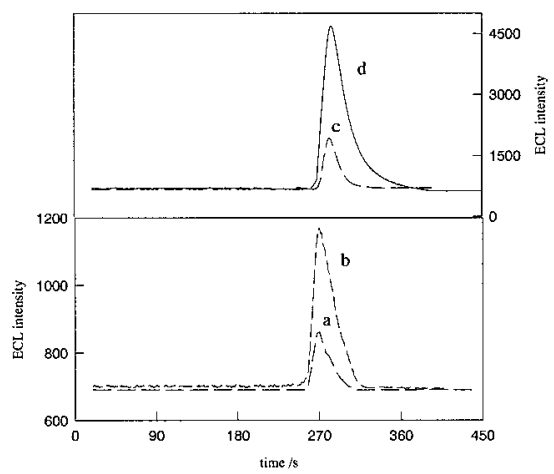

Fig. 5 Typical ECL response for different concentrations of CPM. (a) $2 \mu \mathrm{M}$, (b) $10 \mu \mathrm{M}$, (c) $0.1 \mathrm{mM}$ and (d) $0.5 \mathrm{mM}$.

less protonation of amines: ${ }^{19}$ however, above $\mathrm{pH} 8$, the emitted light decreased, which may be ascribed to the reduced availability of $\mathrm{Ru}(\mathrm{bpy})_{3}{ }^{3+}$ due to a competitive reaction with the $\mathrm{OH}^{-}$ion. This $\mathrm{pH}$-dependence might also be consistent with the earlier reports that showed maximum ECL activity of the tertiary amine occurs at a $\mathrm{pH}$ value lower than the $\mathrm{p} K_{\mathrm{a}}$ of the amine. ${ }^{20}$

\section{Analytical performance}

Therefore, the following experimental conditions were selected as the optimal conditions: applied potential, $1.2 \mathrm{~V}$; injection voltage, $10 \mathrm{kV}$; injection time, $10 \mathrm{~s}$; separation voltage, $15 \mathrm{kV} ; \mathrm{pH}, 8.0$. The typical ECL response curves for different concentrations of CPM are shown in Fig. 5. It can be seen that the ECL intensity increased and the peak was broadened as the concentration increased. It is reasonable that at larger concentrations, a larger amount of the analyte can react at the electrode to produce a higher intensity, whereas too much analyst may retard the reaction time. Therefore, in Fig. 6, the linear response curve of the ECL intensity with CPM concentrations, two linear response ranges can be found: at a higher CPM concentration, i.e., between $15 \mu \mathrm{M}$ and $1 \mathrm{mM}$,

$$
y=595.2+7.1 x(r=99.1 \%)
$$

while at a lower concentration, i.e., from $0.8 \mu \mathrm{M}$ to $15 \mu \mathrm{M}$ (the inset of Fig. 6),

$$
y=95.9+35.6 x(r=97.9 \%) .
$$

Here $y$ is the ECL intensity, and $x$ is the CPM concentration in $\mu \mathrm{M}$. Comparing Eqs. (7) with (8), it can be found that the slope of Eq. (8) was much larger than that of Eq. (7), the reason of 


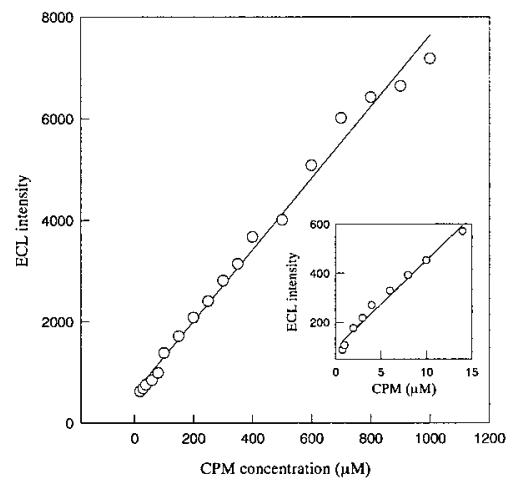

Fig. 6 Linear response of the ECL intensities with the CPM concentrations. The inset is the CPM concentration from 0.8 to $15 \mu \mathrm{M}$.

which may be that at larger concentration, the quantity of the analyte is so high that CPM cannot immediately react at the electrode, and is scattered back into the buffer solution and diluted; however, at lower concentrations, the injected CPM can react completely when it just reaches the reservoir. The experimental detection limit, defined as the lowest concentration of CPM that gives rise to a signal-to-noise of 3 , was found to be $0.5 \mu \mathrm{M}$.

\section{Reproducibility}

The repeatability of this experiment was investigated by four successive injections of $10 \mu \mathrm{M}$ and $500 \mu \mathrm{M}$ CPM, respectively. The interday variation was also studied. All of the results can be found in Table 1, which showed an excellent repeatability for CPM detection with CE-ECL.

\section{Applications of CE-ECL detection for CPM}

Tests of the recovery efficiencies for known amounts of CPM in urine were made. A series of sample solutions were prepared by adding certain amounts of CPM into $10 \mathrm{ml}$ urine of healthy people, and then diluted to $50 \mathrm{ml}$ with double-distilled water. The sample solution was then extracted with a syringe and injected into a $1 \mathrm{ml}$ buffer solution for CPM detection. Table 2 gives the results and recoveries by the standard addition method. Actually, many other substances in urine also possess tertiary amine groups, and may cause an ECL response; however, the migration time at about $270 \mathrm{~s}$ was defined as for $\mathrm{CPM}$, and the dilution effect was considered when calculating the founded CPM.

\section{The association of HSA with CPM}

In this work, equilibrium dialysis was adopted to study the binding of HSA with CPM by incubating $150 \mu \mathrm{L}$ of $200 \mu \mathrm{M}$ HSA and $200 \mu \mathrm{L} 0.01 \mathrm{M} \mathrm{CPM}$ in the dialysis bag at $37^{\circ} \mathrm{C}$. The solution outside of the bag was $4 \mathrm{~mL}$ PBS, and $100 \mu \mathrm{L}$ of this solution was analyzed every half hour. To minimize the possible incidental error of the apparatus, the ECL intensity of 5 $\times 10^{-4} \mathrm{M} \mathrm{CPM}$ was detected and the relative ECL intensity was used to reflect the equilibrium process as follows:

$$
\begin{aligned}
& \text { Relative ECL intensity }= \\
& \text { ECL intensity } \text { outside }_{\text {ECL intensity }} \text { total. }
\end{aligned}
$$

In Fig. 7, with an increase in time, the relative intensity increased, and reached a plateau $(71 \%)$ after $4 \mathrm{~h}$. After the equilibrium, $50 \mu \mathrm{L}$ of the solution outside the dialysis bag (d), and $50 \mu \mathrm{L}$ of the solution in the dialysis bag (e) were put into
Table 1 Reproducibility of successive and interday detection of CPM

\begin{tabular}{ccccrc}
\hline \multirow{2}{*}{$\begin{array}{c}\text { CPM } \\
\text { concentration/ } \mu \mathrm{M}\end{array}$} & \multicolumn{2}{c}{ Migration time/s } & & \multicolumn{2}{c}{ ECL intensity/a.u. } \\
\cline { 2 - 3 } \cline { 5 - 6 } & Mean & RSD, \% & & Mean & RSD, \% \\
\hline $10^{\mathrm{a}}$ & 270 & 0.42 & & 450 & 2.48 \\
$500^{\mathrm{a}}$ & 273 & 0.94 & & 4010 & 3.54 \\
$10^{\mathrm{b}}$ & 271 & 1.65 & & 452 & 2.69 \\
$500^{\mathrm{b}}$ & 275 & 2.02 & & 3998 & 4.22 \\
\hline
\end{tabular}

a. The consecutive detection of four injections of CPM.

b. The interday detection of CPM.

Table 2 Determination of CPM determination in urine using CE-ECL

\begin{tabular}{ccc}
\hline Added CPM $/ \mathrm{mg}$ & Founded CPM $\mathrm{a} / \mathrm{mg}$ & Recovery, \% \\
\hline 48.8 & $47.8 \pm 0.5$ & 98.0 \\
97.7 & $96.2 \pm 1.0$ & 98.5 \\
146.5 & $143.0 \pm 2.2$ & 97.6 \\
198.5 & $195.1 \pm 3.0$ & 98.5 \\
244.2 & $241.3 \pm 4.0$ & 98.8 \\
\hline
\end{tabular}

a. Values are mean \pm S.D. $(n=3)$.

the $1.0 \mathrm{~mL}$ PBS buffer, respectively, and the corresponding UVvisible spectra were recorded (Fig. 8). For a comparison, $50 \mu \mathrm{L}$

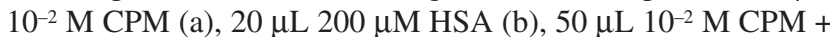
$20 \mu \mathrm{L} 200 \mu \mathrm{M}$ HSA (c) were also injected into $1.0 \mathrm{~mL}$ PBS buffer, and UV-visible spectra were recorded again. Comparing curve $d$ with curve a, the similarity of the peaks implied that only CPM could be found in the outside solution. Furthermore, it can be seen that the spectrum in the dialysis bag (e) is greatly different from the peak of HSA (b), CPM (a) and the simple associate spectrum of HSA with CPM without culture (c), which confirmed the binding of HSA and CPM under the experimental conditions.

Subsequently, the binding constant of HSA and CPM was estimated by the isotherm curve. In a series of dialysis bags, 50 $\mu \mathrm{L} 200 \mu \mathrm{M}$ HSA and different volumes of $10^{-2} \mathrm{M}$ CPM were mixed, and then immersed in $2 \mathrm{~mL}$ of the PBS buffer. The ECL intensity of the outside solution was detected after the binding was balanced (about $4 \mathrm{~h}$ ). Figure 9 shows the relationship between the relative ECL intensity and the associated CPM with the injected CPM concentration. At the given HSA concentration, we could use the Langmuir isotherm equation, ${ }^{21}$

$$
\theta=\frac{K c}{1+K c},
$$

where $\theta$ is the binding coefficient, $K$, the binding constant, and $c$, the CPM concentration. Furthermore,

$$
\theta=\frac{\alpha_{\mathrm{c}}}{\alpha_{\max }}
$$

where $\alpha_{c}$ is the CPM binding amount (unit: mol) at different concentrations and $\alpha_{\max }$ is the maximum binding amount under this condition. Therefore, by combining of Eqs. (10) and (11), the following equation can be obtained:

$$
\alpha_{c}=\frac{K c \alpha_{\max }}{1+K c}
$$




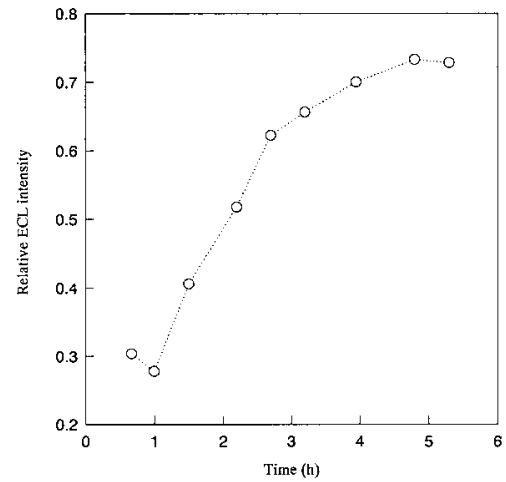

Fig. 7 Relationship of the relative ECL intensity with the reaction time.

The bound CPM in Fig. 9 can be non-linearly fitted using the above equation, and expressed as

$$
\alpha_{\mathrm{c}}=2.24 \times 0.41 c /(1+0.41 c) \quad\left(q_{\mathrm{r}}=2.14 \times 10^{-4}\right) .
$$

Considering the units in the plot, for the HSA used in this section, the maximum binding amount is $2.24 \times 10^{-4} \mathrm{M}$, and the binding constant is $4.1 \times 10^{3} \mathrm{M}^{-1}$.

\section{Conclusions}

In this work, CPM, because of its tertiary amine group, was firstly detected using the $\mathrm{CE}-\mathrm{Ru}(\mathrm{bpy}){ }_{3}{ }^{2+} \mathrm{ECL}$ technique as a simple, fast and selective method. The optimal analytical conditions, the reproducibility and the linearity were considered in detail. Two linear responses to CPM, i.e., from $15 \mu \mathrm{M}$ and 1 $\mathrm{mM}$ and from $0.8 \mu \mathrm{M}$ to $15 \mu \mathrm{M}$, were obtained with a detection limit of $0.5 \mu \mathrm{M}$. The binding of CPM with HSA was estimated to be $4.1 \times 10^{3} \mathrm{M}^{-1}$ by CE-Ru(bpy) ${ }_{3}^{2+}$ ECL. Therefore, CE$\mathrm{Ru}(\mathrm{bpy})_{3}{ }^{2+}$ ECL is a well-established, sensitive detection technique for the determination of amine-containing pharmaceuticals, purines and DNA without any derivation.

\section{Acknowledgements}

The authors give thanks for the supports and informational discussions with Prof. S. Yao of Hunan University (China) and the President Fund Support of South China Agriculture University.

\section{References}

1. British Pharmacopoeia, 1980, London, 105.

2. T. Takagaki, M. Matsuda, Y. Mizuki, and Y. Terauchi, $J$. Chromatogr., B, 2002, 776, 169.

3. A. Y. Qu, D. F. Xu, L. X. Ren, X. L. Jin, and S. M. Cai, Electroanalysis, 1997, 17, 35.

4. Y. M. Issa and A. S. Amin, Analyst, 1996, 24, 139.

5. A. L. Crego and M. L. Marina, Comprehensive Anal. Chem., 2005, 45, 225.

6. M. T. Veledo, P. Lara-Quintanar, M. de Frutos, and J. C. Díez-Masa, Comprehensive Anal. Chem., 2005, 45, 305.

7. M. R. N. Monton and S. Terabe, Anal. Sci., 2005, 21, 5 .

8. W. Siangproh, O. Chailapakul, R. Laocharoensuk, and J.

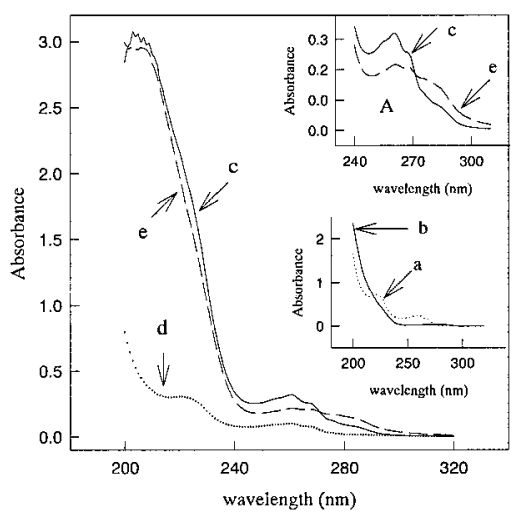

Fig. $8 U$ UV-visible spectra of $50 \mu \mathrm{L} 10^{-2} \mathrm{M} \mathrm{CPM}$ (a), $20 \mu \mathrm{L} 200 \mu \mathrm{M}$ HSA (b), $50 \mu \mathrm{L} 10^{-2} \mathrm{M}+20 \mu \mathrm{L} 200 \mu \mathrm{M}$ HSA (c), $50 \mu \mathrm{L}$ of the solution outside the dialysis bag (d), and $50 \mu \mathrm{L}$ of the solution in the dialysis bag (e). Inset $\mathrm{A}$ is an enlargement of the right figure from the $240 \mathrm{~nm}$ to $310 \mathrm{~nm}$.

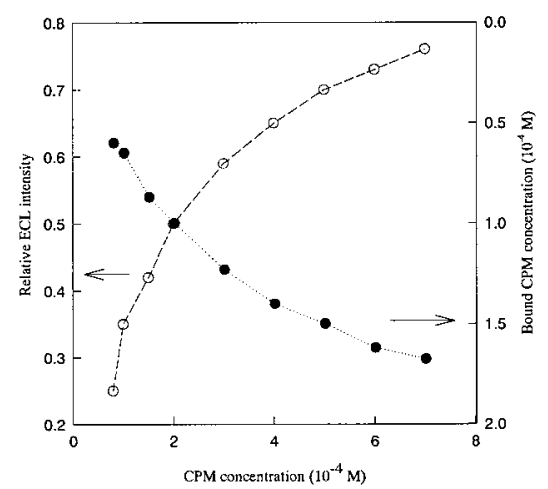

Fig. 9 Relationship of the relative ECL intensity outside the dialysis bag and the bound CPM on the CPM concentration.

Wang, Talanta, 2005, 67, 903.

9. H. B. Qiu, J. L. Yan, X. H. Sun, J. F. Liu, W. D. Cao, X. R. Yang, and E. K. Wang, Anal. Chem., 2003, 75, 5435.

10. J. F. Liu, X. R. Yang, and E. K. Wang, Electrophoresis, 2003, 24, 3131.

11. L. Fang, X. Yin, X. Sun, and E. Wang, Anal. Chim. Acta, 2005, 537, 25.

12. P. R. Haddad, Anal. Lett., 1999, 32, 2909.

13. Y. Gao, Y. Tian, and E. Wang, Anal. Chim. Acta, 2005, $545,137$.

14. X. Wang and D. R. Bobbitt, Anal. Chim. Acta, 1999, 383, 213.

15. H. P. Hendrichkson, P. Anderson, X. Wang, Z. Pittman, and D. R. Bobbitt, Microchem. J., 2000, 65, 189.

16. T. Kuwabara, T. Noda, H. Ohtake, T. Ohtake, S. Toyama, and Y. Ikariyama, Anal. Biochem., 2003, 314, 30.

17. R. D. Gerardi, N. W. Barnett, and S. W. Lewis, Anal. Chim. Acta, 1999, 378, 1 .

18. S. N. Brune and D. R. Bobbitt, Talanta, 1991, 38, 419

19. W. Knight and G. M. Greenway, Analyst, 1995, 120, 2543.

20. J. F. Liu, W. D. Cao, X. R.Yang, and E. K. Wang, Talanta, 2003, 59, 453.

21. X. C. Fu, W. X. Shen, and T. Y. Yao, "Physical Chemistry", 1989, High Education Press, Beijing, China, 937. 